\title{
Produtividade e qualidade do óleo essencial de capim-limão, Cymbopogon citratus, DC., submetido a diferentes lâminas de irrigação
}

\author{
PINTO D.A. ${ }^{1}$; MANTOVANI E.C. ${ }^{1}$; MELO E. de C. ${ }^{1}$; SEDIYAMA G.C. ${ }^{1}$; VIEIRA G.H.S..$^{{ }^{\star}}$ \\ ${ }^{1}$ Departamento de Engenharia Agrícola, Universidade Federal de Viçosa, CEP 36.570-000, Viçosa-Brasil. ${ }^{2}$ Instituto \\ Federal de Educação, Ciência e Tecnologia do Espírito Santo, campus Santa Teresa. CEP 29.660-000, Santa \\ Teresa, Brasil. *ghsvieira@gmail.com.
}

RESUMO: Devido às poucas informações sobre as práticas de cultivo do capim-limão (Cymbopogon citratus, DC.) objetivou-se avaliar o efeito de lâminas de irrigação sobre: a produção de biomassa, o rendimento e composição do óleo essencial. O experimento foi instalado em ambiente protegido para possibilitar o controle das lâminas de irrigação e avaliar a viabilidade para situações em que as condições climáticas normais sejam inadequadas. 0 delineamento experimental foi em blocos inteiramente casualizados com cinco tratamentos e três repetições. Os dados foram submetidos à análise de variância pelo tese $\mathrm{F}$ e as médias comparadas pelo teste de Tukey a $5 \%$ de probabilidade. Na etapa um, os tratamentos consistiram da aplicação de lâminas referentes a 50\%, 75\%, 100\%,125\% da evapotranspiração da cultura (ETc), irrigando duas vezes por semana e de $100 \%$ da evapotranspiração da cultura (ETc), irrigando uma vez por semana, sendo denominados de T1, T2, T3, T4 e T5, respectivamente. Na etapa dois, os tratamentos consistiram da aplicação de lâminas referentes a 50\%, $75 \%, 100 \%$, $125 \%$ da ETc irrigando uma vez por semana e de $100 \%$ da ETc, irrigando a cada 14 dias, sendo denominados de T6, T7, T8, T9 e T10 respectivamente. O corte do capim-limão foi realizado após 60 dias do início dos tratamentos. Avaliou-se a altura de plantas, o número de perfilhos por touceira, a massa seca da parte aérea, o rendimento e a composição do óleo essencial. $O$ T5, caracterizado por estresse hídrico e intervalo de irrigação moderado, foi o que apresentou a maior produção de matéria seca, maior produtividade do capim-limão e maior estimativa da produtividade de óleo essencial e maior concentração de citral, na primeira etapa. Na etapa dois, o T6, correspondente ao estresse hídrico crescente e acentuado, foi o que apresentou maior estimativa da produtividade de óleo essencial. De acordo com os resultados observados, não foi possível definir a melhor lâmina, porém, concluiu-se que uma única irrigação semanal, para as condições estudadas neste experimento promoveu o melhor resultado.

Palavras-chave: capim-limão, irrigação, óleo essencial

ABSTRACT: Growth production and essential oil quality of lemongrass (Cymbopogon citratus) under different irrigation depths. The aim of this work was to evaluate the effect of different irrigation depths on biomass production, yield and composition of lemongrass (Cymbopogon citratus)essential oil, because of poor information on cultivation practices. The experiment was set up in a protected environment to control irrigation and also to evaluate situations in which the normal climatic conditions are inadequate. A complete randomized block design was incorporated with five treatments and three replications, and averages were compared using the Tukey's test at $5 \%$ probability. In phase one, the treatments consisted of irrigation depths relating to $50 \%, 75 \%, 100 \%, 125 \%$ of crop evapotranspiration (ETc), irrigating twice a week, and irrigating only once a week for a sample supplied with $100 \%$ of the crop evapotranspiration (ETc); these were labeled T1, T2, T3, T4 and T5, respectively. In phase two, the treatments consisted of depths of $50 \%, 75 \%, 100 \%, 125 \%$ of the ETc, irrigating once a week, and another with $100 \%$ of the ETc, irrigating every 14 days, which were denominated T6, T7, T8, T9 and T10, respectively. Harvest of the lemon grass was done after 60 days of treatment. Plant height, number of tillers per plant, dry mass of the shoots, yield and composition of essential oil were evaluated. Treatment $\mathrm{T} 5$, characterized by water stress and a moderate

Recebido para publicação em 09/04/2012

Rev. Bras. PI. Med., Campinas, v.16, n.1, p.54-61, 2014. 
irrigation interval, presented the highest dry matter production, lemongrass productivity, estimate of essential oil productivity and concentration of citral in the first phase. In phase two of this work, T6,characterized by a sharp increaseof water stress, presented the greatest estimate of essential oil productivity. According to the results observed, we could not define an optimal irrigation depth; however, we concluded that a single irrigation per week for the conditions of this experiment provided the best result.

Keywords: lemongrass, irrigation, essential oil.

\section{INTRODUÇÃO}

O Cymbopogon citratus (D.C.) Stapf é originário da Î́ndia, sendo conhecido popularmente como capim-limão, capim-santo, capim-cidreira. A espécie é cultivada para produção comercial de óleo essencial, denominado internacionalmente como "lemon grass". Seu óleo é amplamente utilizado para fins medicinais, sobretudo na forma de chá, e tem seu uso e aplicação nas indústrias farmacêuticas, alimentícias, de cosméticos e perfumaria, bem como para obtenção do citral, o principal componente do seu óleo essencial (Martinazzo et al., 2007).

O capim-limão é cultivado em ambiente não protegido em praticamente todos os países tropicais. No Brasil, a produção dessa planta ocorre destacadamente nas regiões Sul e Sudeste. Em estudo realizado no estado do Paraná, Gomes et al. (2007) observaram que apenas no núcleo de Jacarezinho foi registrada a existência de um ambiente protegido para produção de mudas por perfilhos.

No estado do Paraná, maior produtor de plantas medicinais aromáticas do País, a produção de capim-limão ocupa posição de destaque (SEAB/ Paraná, 2008). A safra 2007/2008 totalizou 2.029,7 t, ocupando 102,6 ha distribuídos em 21 municípios produtores. O valor bruto da produção agrícola desta safra totalizou $\mathrm{R} \$ 1$ 1.045.308,00. Estas cifras levaram este produto a ser classificado como um dos "produtos especiais" mais valorizados no Paraná.

O termo óleo essencial é empregado para designar líquidos oleosos, voláteis, dotados de aroma forte, quase sempre agradável, insolúveis em água e solúveis em solventes orgânicos (Silva et al., 1995).

Nascimento et al. (2003) relatam que o componente mais importante do óleo essencial do capim-santo é o citral, sendo uma mistura de isômeros, geranial (a-citral) e neral (b-citral), que é utilizada pela indústria farmacêutica para síntese de ianonas e vitamina $A$, acompanhado de pequena quantidade de mirceno. Tem ação calmante e espasmolítica comprovada, atribuída à presença do citral, enquanto a atividade analgésica é devida ao mirceno (Matos, 2000).

A qualidade dos fitoterápicos depende de uma série de fatores, mas tem início na identificação correta da espécie e continua no plantio, na colheita, e no beneficiamento. Diversos fatores influenciam a qualidade final do óleo essencial das plantas, tais como: variações climáticas, solo, época de colheita, características genéticas da planta, condições de secagem e tempo de armazenamento (Barbosa et al., 2006).

O cultivo do capim-limão em ambiente protegido pode favorecer sua produção nas entressafras, em condições climáticas não favoráveis e é largamente utilizado para viabilizar a agricultura em regiões desérticas ou muito frias como em países como o Japão, EUA, Canadá, Rússia e Israel. No Brasil, esse tipo de cultivo teve início no final da década de 60, mas a partir do final da década de 80 é que essa prática se difundiu, atingindo a marca de cerca de 10.000 ha cultivados em ambiente protegido (Tivelli, 1998).

Comparando-se o cultivo em condições de campo com o ambiente protegido, percebem-se diferenças na radiação solar, umidade relativa do ar, temperatura do ar e principalmente velocidade do ar, precipitação pluvial e, consequentemente, na evapotranspiração.

Pereira et al. (2002) salientam que a evapotranspiração no interior do ambiente protegido é menor do que no ambiente externo devido não somente à redução do saldo de radiação, mas também devido à menor ventilação e à maior umidade do ar no interior do ambiente.

Nos ambientes protegidos, a utilização da irrigação é imprescindível, uma vez que não se pode contar com as precipitações. No entanto, o manejo da irrigação exige atenção especial por parte do produtor. Para suprir tal demanda das plantas é necessário haver água no solo em quantidade suficiente e sua falta leva a planta a sofrer estresse por deficiência hídrica e o excesso leva ao estresse por acúmulo de água (Mendonça \& Rassini, 2005).

A ação combinada dos fatores que afetam a evapotranspiração das culturas faz com que o consumo de água em condições protegidas seja, em geral, menor que em condições de campo (Silva \& Marouelli, 1998). Reduções entre 20 e $30 \%$ da demanda hídrica acumulada têm sido comumente encontradas em pesquisas realizadas no Brasil

Rev. Bras. Pl. Med., Campinas, v.16, n.1, p.54-61, 2014. 
(Tivelli, 1998).

Considerando os aspectos abordados, e a falta de informações de irrigação na cultura, objetivou-se com este trabalho quantificar o efeito de diferentes lâminas de irrigação e intervalos entre irrigações, na produtividade, altura, número de perfilhos, massa seca, produção e composição do óleo essencial do capim-limão.

\section{MATERIAL E MÉTODOS}

O experimento foi conduzido em uma casade-vegetação na área experimental de Irrigação e Drenagem, do Departamento de Engenharia Agrícola da Universidade Federal de Viçosa, no período de 16 de maio a 14 de julho e de 3 de agosto a 1 de outubro de 2009.

Foi utilizado um ambiente protegido com as seguintes características: a) dimensões: 6,0 x 8,0 x 3,0 m (largura, comprimento e altura); b) cobertura: filme plástico de polietileno de alta densidade de 150 micra, transparente, instalado com peça única; c) telhado lateral de fechamento: foi utilizado sombrite a $30 \%$; d) mureta perimetral: construída em concreto com $0,30 \mathrm{~m}$ de altura e 0,06 $\mathrm{m}$ de largura; e) abertura: $0,30 \mathrm{~m}$ de altura, entre a mureta perimetral e o sombrite. A implantação do experimento em ambiente protegido foi definida com o intuito de evitar a influência de eventuais precipitações, embora possa ser uma opção para produção em locais onde as condições climáticas são inadequadas.

O solo da área experimental é classificado como Latossolo Vermelho Amarelo distrófico (Embrapa, 1997). Realizaram-se as análises químicas do solo para recomendação de adubação em conformidade com as necessidades da cultura do capim-limão em fase de crescimento. Fez-se análise textural e a determinação da curva de retenção de água do solo, estabelecendo, assim, as umidades do solo no ponto de murcha permanente (PMP) e na capacidade de campo (CC), referências para a definição das lâminas de irrigação a serem aplicadas.

Considerando a disponibilidade total de água no solo como a quantidade de água existente entre a CC e o PMP, utilizou-se como fator $f$ para definir a disponibilidade real de água no solo o valor de 50\% (Bernardo et al., 2006). Na Tabela 1 são apresentados os resultados das análises físicas do solo.

Utilizaram-se mudas de capim-limão provenientes de matrizes existentes no grupo de plantas medicinais Entre Folhas da UFV, plantadas com espaçamento de $0,30 \times 0,30 \mathrm{~m}$ em novembro de 2008. Após 180 dias foi realizada a primeira poda e em seguida iniciada a aplicação dos tratamentos. Neste mesmo dia, houve uma adubação com NPK 20-5-20 na dosagem de $325 \mathrm{~kg} \mathrm{ha}^{-1}$, considerando os resultados da análise química e recomendação de Blank et. al (2007) e aplicação de uma lâmina de irrigação para atingir a capacidade de campo do solo. Após 60 dias do início dos tratamentos, realizou-se a poda para a coleta dos dados.

O sistema de irrigação utilizado foi de tipo localizado, via gotejamento, com vazão de 0,93 $\mathrm{L} \mathrm{h}^{-1}$, intensidade de aplicação de 4,12 $\mathrm{mm} \mathrm{h}^{-1}$, pressão de serviço de $50 \mathrm{kPa}$ e espaçamento entre emissores de 0,15 m. A avaliação do sistema de irrigação resultou na determinação do Coeficiente de Uniformidade de Christiansen (CUC) de 98\% (Mantovani et al., 2009).

A reposição das lâminas de irrigação na primeira etapa ocorreu de $3 \mathrm{em} 3$ dias e na segunda etapa de $7 \mathrm{em} 7$ dias, sendo que em cada etapa houve um tratamento com o dobro desses intervalos.

$\mathrm{Na}$ etapa um do experimento, de 16 de maio a 14 de julho o delineamento estatístico foi em blocos inteiramente casualizados com 5 tratamentos e 3 repetições, sendo 6 plantas por parcela, considerando-se 2 plantas úteis por parcela. Cada tratamento constituiu um regime hídrico: sendo tratamento $1\left(\mathrm{~T}_{1}\right)=50 \%$ da ETc (estresse hídrico crescente); tratamento $2\left(\mathrm{~T}_{2}\right)=75 \%$ da ETc (estresse hídrico crescente e moderado); tratamento $3\left(\mathrm{~T}_{3}\right)=$ $100 \%$ da ETc (sem estresse hídrico); tratamento 4 $\left(\mathrm{T}_{4}\right)=125 \%$ da ETc (sem estresse e com excesso de água), todos irrigando duas vezes por semana e o tratamento $5\left(T_{5}\right)=100 \%$ da ETc irrigando uma vez por semana (estresse hídrico e intervalo entre irrigação moderado), durante 60 dias.

Com os resultados obtidos e analisados da etapa um do experimento, montou-se a segunda etapa, de 3 de agosto a 1 de outubro de 2009,

TABELA 1. Resultado das análises físico-hídricas do solo (granulometria e retenção de água do solo) para o solo da área experimental

\begin{tabular}{|c|c|c|c|c|c|c|c|}
\hline \multirow{3}{*}{ Solo } & \multicolumn{5}{|c|}{ Granulometria } & \multicolumn{2}{|c|}{ Umidade } \\
\hline & Areia grossa & Areia fina & Silte & Argila & $\begin{array}{c}\text { Densidade } \\
\text { do solo }\end{array}$ & PMP & $\mathrm{CC}$ \\
\hline & \multicolumn{4}{|c|}{$\mathrm{dag} / \mathrm{kg}$} & $\mathrm{g} / \mathrm{cm}^{3}$ & \multicolumn{2}{|c|}{$\%$ (em peso) } \\
\hline $\mathrm{S}_{1}$ & 28 & 12 & 2 & 58 & 1,07 & 21,79 & 38,42 \\
\hline
\end{tabular}

Rev. Bras. PI. Med., Campinas, v.16, n.1, p.54-61, 2014. 
com o intuito de verificar quais as melhores lâminas e frequência de irrigação. $O$ delineamento experimental foi o mesmo da etapa 1. Cada tratamento constituiu um regime hídrico, sendo: $\mathrm{T}_{6}=$ $50 \%$ da ETc (estresse hídrico crescente acentuado); $\mathrm{T}_{7}=75 \%$ da ETc (estresse hídrico crescente $\mathrm{e}$ moderado); T8 $=100 \%$ da ETc (sem estresse hídrico); T9 = $125 \%$ da ETc (sem estresse hídrico e com excesso), irrigando uma vez por semana e $T_{10}$ $=100 \%$ da ETc irrigando uma vez a cada 14 dias (estresse hídrico moderado e intervalo de irrigação elevado), durante 60 dias.

O manejo da irrigação foi conduzido com auxílio do software IRRIPLUS ${ }^{\circledR}$, que calcula a evapotranspiração da cultura a partir da evapotranspiração de referência, pelo método de Penman-Monteith (Allen et al., 1998), multiplicando-a pelos coeficientes de ajuste $\mathrm{Kc}$, Ks e KI. Para as duas etapas utilizou-se valores de Kc de 0,6; 0,8 e 1,05 para as fases inicial, desenvolvimento e final, respectivamente. Os valores de Ks foram do modelo logaritmo. Para o ajuste devido à localização (KI) da irrigação (irrigação por gotejamento) utilizouse o modelo de Keller-Bliesner, que tem sido recomendado para uso geral (Mantovani et al., 2009).

Os dados meteorológicos diários (umidade relativa, temperaturas máxima, média e mínima, velocidade do vento e radiação solar) foram obtidos em uma estação meteorológica automática modelo Micrometos, instalada dentro do ambiente protegido.

Ao final do experimento, antes de se fazer a poda das plantas, determinou-se a altura das plantas úteis com uma trena, medindo-se do solo até o final da folha. Após esse processo, as folhas foram cortadas a $0,20 \mathrm{~m}$ do solo, sendo imediatamente pesadas, para determinação da massa de matéria fresca total (MFT). Depois o material foi colocado em estufa a $60^{\circ} \mathrm{C}$, até massa constante para determinação da matéria seca total (MST). Para a obtenção dos valores de produtividade, utilizou-se uma balança de precisão de $0,01 \mathrm{~g}$. A partir dos valores do peso da matéria seca total e considerando o número de plantas por ha, de acordo com o espaçamento utilizado, o valor da produtividade foi calculado em toneladas por ha.

O teor de água das amostras de plantas foi determinado pelo método gravimétrico recomendado pela ASAE (2000) para forrageiras e plantas similares, utilizando-se $25 \mathrm{~g}$ de produto, em três repetições, em estufa com circulação forçada de ar a $103 \pm 2^{\circ} \mathrm{C}$, durante $24 \mathrm{~h}$.

As análises do óleo essencial foram realizadas no Laboratório de Análise e Síntese de Agroquímicos (LASA), pertencente ao Departamento de Química da Universidade Federal de Viçosa.

O óleo essencial foi extraído por hidrodestilação, utilizando o aparelho Clevenger adaptado a um balão de $2 \mathrm{~L}$, onde foi colocada uma amostra de $90 \mathrm{~g}$ da planta fresca, juntamente com $1 \mathrm{~L}$ de água destilada. Para facilitar a extração do óleo essencial, as folhas foram cortadas transversalmente a cada 0,02 m. O tempo de extração foi de 90 minutos, contados a partir do momento da ebulição, tempo esse determinado por testes preliminares.

A separação da fase aquosa e do óleo essencial foi executada com três extrações usando $50 \mathrm{~mL}$ de pentano como solvente extrator, para cada extração, em um funil de separação. A fase aquosa foi descartada e a fase orgânica secada com sulfato de magnésio anidro $\left(\mathrm{MgSO}_{4}\right)$ em excesso, para retirada total de água. Em seguida, a solução foi filtrada e o solvente evaporado sob pressão reduzida, a $40^{\circ} \mathrm{C}$, no evaporador rotativo, até atingir massa constante. A quantificação do óleo essencial foi efetuada por meio de pesagem, em balança analítica com precisão de $0,0001 \mathrm{~g}$. Posteriormente, foram expressos em porcentagem de óleo em relação à matéria fresca do produto (\%m.f.).

O óleo foi acondicionado em frascos de vidro de $5 \mathrm{~mL}$, armazenados sob atmosfera de nitrogênio, envoltos em papel alumínio e mantidos sob refrigeração a $4^{\circ} \mathrm{C}$, até o momento da análise qualitativa (cromatografia).

A identificação dos compostos foi realizada utilizando-se a técnica de cromatografia gasosa acoplada à espectrometria de massas (CG-EM), em equipamento Shimadzu, modelo GC 17A, com detector seletivo de massa, modelo QP 5000 - Shimadzu. A coluna cromatográfica utilizada foi do tipo capilar de sílica fundida com fase estacionária DB- 5 de $0,25 \mu \mathrm{m}$ de espessura, $30 \mathrm{~m}$ de comprimento e $0,25 \mathrm{~mm}$ de diâmetro interno. Utilizou-se hélio como gás carreador a um fluxo de $1,8 \mathrm{~mL} \mathrm{~min}{ }^{-1}$. A temperatura foi de $220^{\circ} \mathrm{C}$ no injetor e $240^{\circ} \mathrm{C}$ no detector. A temperatura inicial do forno foi mantida a $40^{\circ} \mathrm{C}$ por dois minutos, sendo programada para ter acréscimos de $3^{\circ} \mathrm{C}$ a cada minuto até atingir a temperatura máxima de $240^{\circ} \mathrm{C}$, na qual foi mantida por mais 20 minutos fornecendo um tempo de análise de 88 minutos. A razão de split utilizada foi de 1:5 e o tempo de corte do solvente de 5 minutos. Foram detectados no espectrômetro de massas somente íons com a razão carga massa $\mathrm{m} / \mathrm{z}$ entre 30 e 500 .

$\mathrm{O}$ volume da amostra injetado foi de $1 \mu \mathrm{L}$, na concentração de 10.000 ppm, utilizando como solvente o hexano. A identificação dos compostos foi realizada por comparação dos espectros de massas sugeridos no aparelho e pelo índice de Retenção de Kovats (índice de retenção relativo) de cada componente (Lanças, 1993).

As análises de quantificação dos

Rev. Bras. PI. Med., Campinas, v.16, n.1, p.54-61, 2014. 
constituintes do óleo essencial foram realizadas em cromatógrafo a gás Shimadzu GC-17 A, equipado com detector de ionização de chama e coluna capilar de sílica fundida com fase estacionária DB- 5 de 0,25 $\mu \mathrm{m}$ de espessura, $30 \mathrm{~m}$ de comprimento e $0,25 \mathrm{~mm}$ de diâmetro interno. Utilizou-se nitrogênio como gás carreador a um fluxo de $1,33 \mathrm{~mL} \mathrm{~min}^{-1}$. A temperatura inicial da coluna foi mantida a $60^{\circ} \mathrm{C}$ por um minuto, sendo programada para ter acréscimos de $3^{\circ} \mathrm{C}$ a cada minuto até atingir a temperatura máxima de $240^{\circ} \mathrm{C}$, atingindo tempo de análise de 61 minutos. A razão de split foi 1:10 e o tempo de corte do solvente de 5 minutos. As temperaturas do injetor e do detector foram fixadas em $250^{\circ} \mathrm{C}$.

$\mathrm{O}$ volume da amostra injetado foi de $1 \mu \mathrm{L}$, na concentração de 2000 ppm, utilizando como solvente o diclorometano HPLC. Os constituintes foram quantificados baseando-se na comparação dos tempos de retenção dos compostos, que foram similares nas duas técnicas. Utilizou-se o método de normalização em que o valor total das áreas dos picos é considerado $100 \%$ e a porcentagem de cada sinal é calculada por meio de sua área.

Com os dados obtidos, procedeu-se à análise de variância, seguida de teste de médias ao nível de $5 \%$ de probabilidade.

\section{RESULTADOS E DISCUSSÃO}

Na Tabela 2, apresenta-se o resumo do teste de médias para altura, massa seca (MS), número de perfilhos $\left(\mathrm{N}^{\circ}\right)$, produtividade (Prod), rendimento de óleo (R.O.) e estimativa de produtividade de óleo essencial (Estimativa) da etapa I do experimento.

Conforme observado na Tabela 2, a massa seca e, consequentemente, a produtividade do capim-limão e a produtividade do óleo essencial foram as variáveis que apresentaram diferenças significativas entre os tratamentos. O tratamento T5 foi o que resultou na maior produtividade de massa seca e Estimativa da produtividade do óleo. $\mathrm{O}$ tratamento $\mathrm{T} 1$ proporcionou o maior rendimento de óleo essencial. Na Figura 1 apresenta-se o rendimento de óleo essencial e as lâminas de irrigação de cada tratamento.

Para a mesma frequência de irrigação, a lâmina que atendeu $100 \%$ da demanda hídrica da cultura proporcionou o maior rendimento de óleo e, com irrigação em excesso (125\%) houve decréscimo do rendimento. O maior intervalo entre irrigações (T5) pareceu reduzir o rendimento de óleo.

Homer et al. (2000), estudando a espécie de planta medicinal Melaleuca Alternifólia (Myrtaceae), constataram que a deficiência hídrica severa diminui o teor de óleo essencial, porém não influencia na composição química dos principais componentes do óleo essencial.

Porém, Handique \& Gupta (1984) registraram que o cultivo de Cymbopogon citratus, nas condições de Jorhart (Índia), mostrou grande variação no conteúdo de óleo essencial durante o ano. Ao relacionar os rendimentos de óleo com as variações de temperatura, evidenciaram que o aumento ou diminuição desta, têm uma pequena relação com o conteúdo de óleo.

$\mathrm{Na}$ Tabela 3, apresenta-se o resumo do teste de médias para os componentes do óleo essencial do capim-limão: geranial (a-citral), neral (b-citral), mirceno e o composto citral (a-citral + b-citral).

Para o componente Citral, observa-se que os maiores valores foram obtidos no tratamento com irrigação atendendo a $100 \%$ da demanda hídrica da cultura, com intervalo entre irrigações moderado. Para o menor fornecimento hídrico (25\%), houve menor rendimento do componente, o que indica que o estresse hídrico pode afetar a formação deste componente.

De maneira oposta, o componente Neral apresentou menores valores para maiores valores de lâminas de irrigação. Para os componentes Geranial e Mirceno, não houve diferença significativa entre os tratamentos, pelo teste Tukey a $5 \%$ de probabilidade.

Na Tabela 4, apresenta-se o resumo do teste de médias para altura, massa seca (M.S.), perfilho

TABELA 2. Teste de Tukey para as variáveis: altura $(\mathrm{m})$, massa seca $(\mathrm{g})$, perfilho $\left(\mathrm{N}^{\circ}\right)$, produtividade $\left(\mathrm{t} \mathrm{ha} \mathrm{a}^{-1}\right)$, rendimento de óleo essencial (\%) e estimativa de produtividade do óleo (t ha- $\left.{ }^{-1}\right)$ da etapa I do experimento

\begin{tabular}{lcccccc}
\hline Trat & $\begin{array}{c}\text { Altura } \\
(\mathbf{m})\end{array}$ & $\begin{array}{c}\text { M. S. } \\
(\mathbf{g})\end{array}$ & $\begin{array}{c}\text { Perfilhos } \\
\left(\mathbf{N}^{\mathbf{0}}\right)\end{array}$ & $\begin{array}{c}\text { Prod } \\
\left(\mathbf{t ~ h a} \mathbf{~}^{-1}\right)\end{array}$ & $\begin{array}{c}\text { R.O. } \\
(\% \text { m.f.) }\end{array}$ & $\begin{array}{c}\text { Estimativa } \\
\left(\mathbf{t ~ h a}^{-1}\right)\end{array}$ \\
\hline 1 & $1,23 \mathrm{a}$ & $327,55 \mathrm{~b}$ & $147,67 \mathrm{a}$ & $32,69 \mathrm{~b}$ & $2,4082 \mathrm{a}$ & $0,163 \mathrm{~b}$ \\
2 & $1,25 \mathrm{a}$ & $356,08 \mathrm{~b}$ & $141,00 \mathrm{a}$ & $32,29 \mathrm{~b}$ & $2,4777 \mathrm{a}$ & $0,163 \mathrm{~b}$ \\
3 & $1,13 \mathrm{a}$ & $333,02 \mathrm{~b}$ & $114,67 \mathrm{a}$ & $37,00 \mathrm{~b}$ & $2,5674 \mathrm{a}$ & $0,183 \mathrm{~b}$ \\
4 & $1,17 \mathrm{a}$ & $343,50 \mathrm{~b}$ & $118,00 \mathrm{a}$ & $30,33 \mathrm{~b}$ & $2,4633 \mathrm{a}$ & $0,153 \mathrm{~b}$ \\
5 & $1,25 \mathrm{a}$ & $500,44 \mathrm{a}$ & $126,00 \mathrm{a}$ & $55,60 \mathrm{a}$ & $2,5169 \mathrm{a}$ & $0,255 \mathrm{a}$ \\
\hline C.V & 4,01 & 17,95 & 21,15 & 15,53 & 10,56 & 14,12 \\
\hline
\end{tabular}

Médias seguidas pela mesma letra não diferem estatisticamente entre si pelo teste Tukey com $5 \%$ de probabilidade

Rev. Bras. Pl. Med., Campinas, v.16, n.1, p.54-61, 2014. 


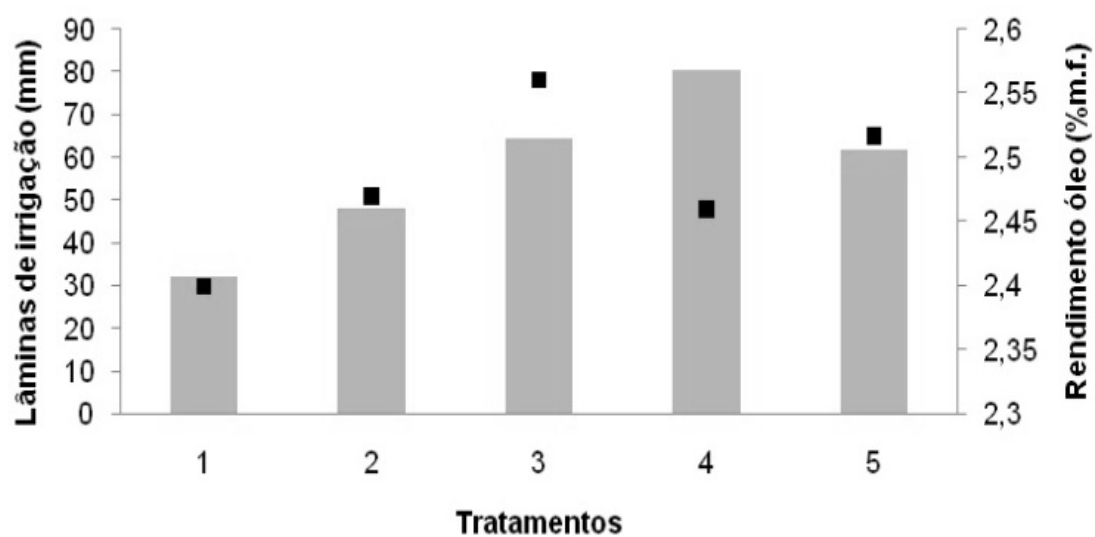

" Lâminas de irrigação $\quad$ Rendimento óleo (m.f\%)

FIGURA 1. Rendimento do óleo essencial de capim-limão em (\%m.f.) e as lâminas de irrigação aplicadas em $(\mathrm{mm})$, para os diferentes tratamentos na etapa I do experimento.

TABELA 3. Teste de Tukey para as variáveis: geranial (a-citral), neral (b-citral), mirceno, e do composto citral (a-citral + b-citral) para a etapa I do experimento.

\begin{tabular}{ccccc}
\hline Trat & \multicolumn{3}{c}{ Componentes } & Citral \\
\cline { 2 - 5 } & $\begin{array}{c}\text { Geranial (a-citral) } \\
(\%)\end{array}$ & $\begin{array}{c}\text { Neral (b-citral) } \\
(\%)\end{array}$ & $\begin{array}{c}\text { Mirceno } \\
(\%)\end{array}$ & $\begin{array}{c}\text { ( a-citral + b-citral) } \\
(\%)\end{array}$ \\
\hline 1 & $46,59 \mathrm{a}$ & $32,91 \mathrm{~b}$ & $13,90 \mathrm{a}$ & $79,50 \mathrm{~b}$ \\
2 & $50,34 \mathrm{a}$ & $37,77 \mathrm{a}$ & $10,87 \mathrm{a}$ & $88,11 \mathrm{~b}$ \\
3 & $48,47 \mathrm{a}$ & $36,66 \mathrm{a}$ & $12,43 \mathrm{a}$ & $85,13 \mathrm{~b}$ \\
4 & $48,80 \mathrm{a}$ & $36,62 \mathrm{a}$ & $13,84 \mathrm{a}$ & $85,42 \mathrm{~b}$ \\
5 & $52,50 \mathrm{a}$ & $35,78 \mathrm{ab}$ & $8,09 \mathrm{a}$ & $88,29 \mathrm{a}$ \\
\hline C.V & 3,90 & 2,52 & 21,98 & 2,01 \\
\hline
\end{tabular}

Médias seguidas pela mesma letra não diferem estatisticamente entre si pelo teste Tukey a $5 \%$ de probabilidade

TABELA 4. Teste de Tukey para as variáveis: altura, massa seca $(\mathrm{g})$, perfilho $(\mathrm{adm})$, produtividade $\left(\mathrm{t} \mathrm{ha}^{-1}\right)$, rendimento de óleo essencial (\%) e estimativa de produtividade do óleo $\left(\mathrm{t} \mathrm{ha}^{-1}\right)$ da segunda etapa do experimento.

\begin{tabular}{lllllll}
\hline Trat & $\begin{array}{l}\text { Altura } \\
(\mathrm{m})\end{array}$ & $\begin{array}{l}\text { M. S. } \\
(\mathrm{g})\end{array}$ & $\begin{array}{l}\text { Perfilho } \\
(\mathrm{adm} .)\end{array}$ & $\begin{array}{l}\text { Prod } \\
\left(\mathrm{t} \mathrm{ha}^{-1}\right)\end{array}$ & $\begin{array}{l}\text { R. O. } \\
(\%)\end{array}$ & $\begin{array}{l}\text { Estimativa } \\
\left(\mathrm{t} \mathrm{ha}^{-1}\right)\end{array}$ \\
\hline 6 & $1,11 \mathrm{a}$ & $429,59 \mathrm{ab}$ & $100,00 \mathrm{a}$ & $47,74 \mathrm{ab}$ & $2,286 \mathrm{a}$ & $0,279 \mathrm{a}$ \\
7 & $1,16 \mathrm{a}$ & $322,24 \mathrm{~b}$ & $96,00 \mathrm{a}$ & $35,80 \mathrm{~b}$ & $2,324 \mathrm{a}$ & $0,152 \mathrm{~b}$ \\
8 & $1,15 \mathrm{a}$ & $429,99 \mathrm{ab}$ & $102,00 \mathrm{a}$ & $47,78 \mathrm{ab}$ & $1,975 \mathrm{a}$ & $0,221 \mathrm{~b}$ \\
9 & $1,13 \mathrm{a}$ & $425,65 \mathrm{ab}$ & $78,00 \mathrm{a}$ & $47,30 \mathrm{ab}$ & $1,928 \mathrm{a}$ & $0,163 \mathrm{~b}$ \\
10 & $1,23 \mathrm{a}$ & $523,38 \mathrm{a}$ & $102,66 \mathrm{a}$ & $58,16 \mathrm{a}$ & $1,850 \mathrm{a}$ & $0,260 \mathrm{~b}$ \\
\hline $\mathrm{C} . V$ & 4,01 & 12,78 & 17,74 & 12,79 & 13,53 & 18,67 \\
\hline
\end{tabular}

Médias seguidas pela mesma letra não diferem estatisticamente entre si pelo teste Tukey a $5 \%$ de probabilidade

(adimensional), produtividade (Prod), rendimento de óleo (R.O.) e estimativa de produtividade de óleo essencial (estimativa) na segunda etapa do experimento.

Observa-se que os tratamentos T7 e T10 diferenciaram-se entre si na produção de matéria seca e na produtividade, com diferenças de 201,14 $\mathrm{g}$ e $22,36 \mathrm{t} \mathrm{h}^{-1}$, respectivamente. O tratamento que obteve o maior rendimento de óleo essencial $(2,32 \%)$ foi o tratamento $T 7$, o qual recebeu a menor

Rev. Bras. PI. Med., Campinas, v.16, n.1, p.54-61, 2014. 


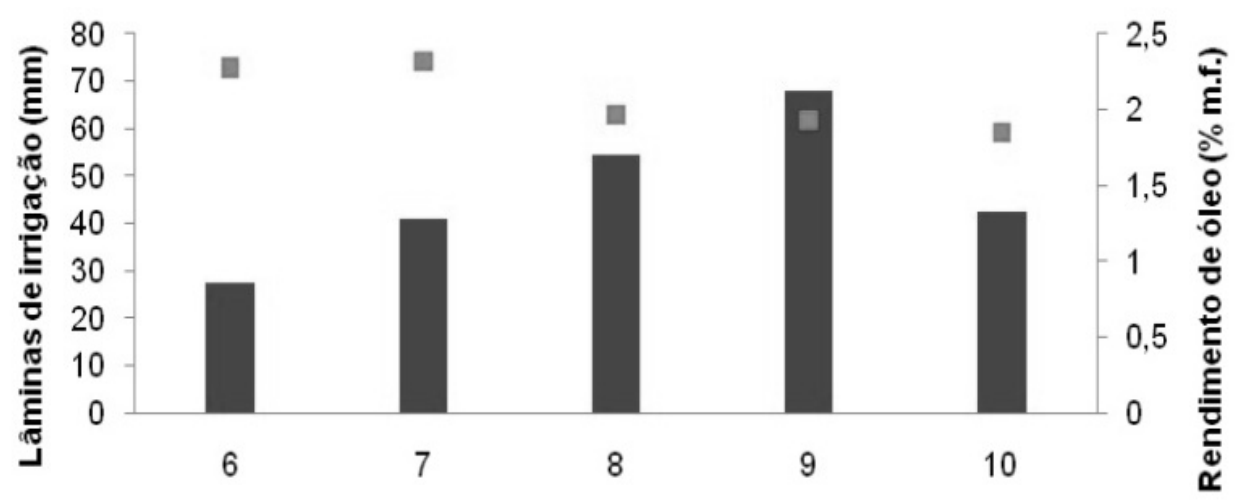

Tratamentos

- Lâminas de irrigação (mm) घRendimento óleo (m.f.\%)

FIGURA 2. Rendimento do óleo essencial de capim-limão em (\%m.f.), e as lâminas de irrigação aplicadas em $(\mathrm{mm})$, para os diferentes tratamentos

lâmina de irrigação durante todo o ciclo, $27,26 \mathrm{~mm}$ (Figura 2).

Comparando os resultados de produtividade e da composição de citral encontrados na etapa um e na etapa dois, pode-se observar que os valores da etapa dois foram superiores. Maiores valores de lâmina de irrigação proporcionaram menores valores de rendimento de óleo, indicando que o déficit hídrico pode favorecer a produção de óleo.

$\mathrm{Na}$ Tabela 5, apresenta-se o resumo do teste de médias para os componentes do óleo essencial do capim-limão: geranial (a-citral), neral (b-citral), mirceno e o composto citral (a-citral + b-citral) da segunda etapa do experimento.

Os componentes de maior destaque encontrados nas duas etapas do experimento foram os mesmos para todos os tratamentos, geranial, neral e mirceno. Já Martinazzo et al. (2007) encontraram que os principais constituintes do óleo essencial do capim-limão foram geranial, neral, geraniol e mirceno.

Para os componentes neral e mirceno, não houve diferença estatística significativa entre os tratamentos. Para os componentes Geranial e Citral, o tratamento T8 se mostrou inferior aos demais, pelo teste de Tukey, ao nível de $5 \%$ de probabilidade.

Diante dos resultados obtidos, nas condições em que o experimento foi conduzido, pode-se concluir que:

O estresse hídrico e o intervalo de irrigação moderados, na primeira etapa, foi o que proporcionou a maior produção de matéria seca, maior produtividade do capim-limão e maior estimativa da produtividade de óleo essencial;

$\mathrm{Na}$ segunda etapa, o estresse hídrico crescente acentuado foi o que promoveu maior estimativa da produtividade de óleo essencial;

Não foi possível definir a melhor lâmina, porém, concluiu-se que uma única irrigação semanal, para as condições estudadas, foi a de

TABELA 5. Teste de Tukey para as variáveis: geranial (a-citral), neral (b-citral), mirceno, e do composto citral (a-citral + b-citral) da segunda etapa do experimento.

\begin{tabular}{ccccc}
\hline Trat & \multicolumn{3}{c}{ Componentes } & Citral \\
\cline { 2 - 5 } & $\begin{array}{c}\text { Geranial (a-citral) } \\
(\%)\end{array}$ & $\begin{array}{c}\text { Neral (b-citral) } \\
(\%)\end{array}$ & $\begin{array}{c}\text { Mirceno } \\
(\%)\end{array}$ & $\begin{array}{c}\text { ( a-citral + b-citral) } \\
(\%)\end{array}$ \\
\hline 6 & $52,34 \mathrm{a}$ & $37,74 \mathrm{a}$ & $6,99 \mathrm{a}$ & $90,08 \mathrm{a}$ \\
7 & $52,22 \mathrm{a}$ & $36,43 \mathrm{a}$ & $8,79 \mathrm{a}$ & $87,73 \mathrm{a}$ \\
8 & $47,05 \mathrm{~b}$ & $33,98 \mathrm{a}$ & $16,8 \mathrm{a}$ & $81,03 \mathrm{~b}$ \\
9 & $52,17 \mathrm{a}$ & $36,68 \mathrm{a}$ & $8,16 \mathrm{a}$ & $89,87 \mathrm{a}$ \\
10 & $52,42 \mathrm{a}$ & $35,73 \mathrm{a}$ & $8,92 \mathrm{a}$ & $88,15 \mathrm{a}$ \\
\hline C.V & 1,32 & 3,43 & 20,16 & 1,42 \\
\hline
\end{tabular}

Médias seguidas pela mesma letra não diferem estatisticamente entre si pelo teste Tukey a $5 \%$ de probabilidade 
melhor resultado;

O efeito do estresse hídrico moderado (100\% da demanda e intervalo de irrigações de 7 dias) não ocasionou diferenças na altura da planta e no número de perfilhos de capim-limão, mas promoveu a maior produtividade de matéria seca, produtividade, e estimativa da produção de óleo essencial, além de maior concentração de citral;

O estresse hídrico mais acentuado (50\% da demanda e intervalo de irrigações de 7 dias), não gerou diferenças na produtividade, matéria seca, altura das plantas e número de perfilhos, mas proporcionou a maior produção do óleo essencial.

\section{REFERÊNCIA}

ALLEN, R.G.; PEREIRA, L.S.; RAES, D.; SMITH, M. Guidelines for computing crop water requeriments. FAO - Irrigation and Drainage. Rome: FAO, 1998. 319 p.

ASAE- American Society of Agricultural Engineers. Standards engineering practices data. Adopted and published by: American Society of Agricultural Engineers, 2000. 1013 p.

BARBOSA, F.F.; BARBOSA, L.C.A.; MELO, E.C.; BOTELHO, F.M.; SANTOS, R.H.S. Influência da Temperatura do Ar de Secagem Sobre o Teor e a Composição Química do Óleo Essencial de lippia alba (mill) N. E. Brown. Revista Química Nova, vol.29, n.6, p.1221-1225, 2006.

BLANK A.F.; ARRIGONI-BLANK M.F.; AMANCIO V.F.; MENDONÇA M.C.; SANTANA FILHO L.G.M. Densidades de plantio e doses de biofertilizante na produção de capim-limão. Horticultura Brasileira, n.25, p. 343-349, 2007.

BERNARDO, S.; SOARES, A.A.; MANTOVANI, E.C. Manual de Irrigação 8.ed. Viçosa: UFV, 2006. 625p.

EMBRAPA. Manual de Métodos de Análise de Solos, $2^{a}$ edição, CNPS-Rio deJaneiro, 1997. 212p.

GOMES, E.C.; NEGRELLE, R.R.B.; DONI FILHO, L.; Caracterização da produção de capim-limão no estado do Paraná, Brasil. Scientia Agraria, Curitiba-PR, v.8, n.4, p.385-390, 2007.

HANDIQUE, A.K., GUPTA, R.K. Variation of oil content in lemon grass as influenced by seasonal changes and its genetics. Indian Perfumer, n.2, p.54-63, 1984.
HOMER, L.E.; LEACH, D.N.; LEA, D.; LEE, L.S.; HENRY, R.J.; BAVERSTOCK, P.R. Natural variation in the essential oil content of Melaleuca alternifolia Cheel (Myrtaceae), Biochemical systematic and ecology, n.28, p. 367-382, 2000.

LANÇAS, F.M. Cromatografia em fase gasosa, São Carlos: Editora Acta, 1993, 254 p.

MANTOVANI, E.C.; BERNARDO, S.; PALARETTI, L.F. Irrigação - Princípios e Métodos. 3.ed. Viçosa: UFV, 2009. 355 p.

MARTINAZZO, A.P.; CORREA, P.C.; MELO, E.C.; BARBOSA, F.F. Difusidade efetiva em folhas de Cymbopogon citratus (D.C) Stapf submetidas à secagem com diferentes comprimentos de corte e temperaturas do ar. Revista Brasileira de Plantas Medicinais, v.9, n.1, p.68-72, 2007.

MATOS, F.J.A. Plantas medicinais: guia de seleção e emprego de plantas usadas em fitoterapia no Nordeste do Brasil. Fortaleza: UFC, 2000. 344 p.

MENDONÇA, F.C., RASSINI, J.B., Curso Teórico Prático de Manejo e Projeto de Irrigação em Pastagens, Embrapa Pecuária Sedeste, 2005. 59 p.

NASCIMENTO, I.B. do; INNECCO, R.; MARCO, C.A.; MATTOS, S.H.; NAGAO, E.O. Efeito do horário de corte no óleo essencial de capim-santo. Revista Ciência Agronômica, v.34, n.2, p.169-172, 2003.

PEREIRA, A.R.; ANGELOCCI, L.R.; SENTELHAS, P.C. Agrometeorologia: fundamentos e aplicações práticas. Guaíba: Agropecuária, 2002. 478 p.

SEAB/Paraná - Secretaria da Agricultura e do Abastecimento do Paraná. Departamento de Economia Rural. Levantamento do valor bruto da produção agropecuária: produtos especiais: safra 2007/2008. Curitiba: SEAB, 2008. 17p.

SILVA, I.; FRANCO, S.L.; MOLINARI, S.L.; CONEGERO, C.I.; MIRANDA NETO, M.H. de; CARDOSO, M.L.C.; SANT'ANA, D.M.; IWANKO, N.S. Noções sobre o organismo humano e utilização de plantas medicinais. Cascavel: Assoeste, 1995. 203p.

SILVA, W.L.C.; MAROUELLI, V.A. Manejo da irrigação em hortaliças no campo e em ambientes protegidos. In: XXVII Congresso Brasileiro de Engenharia Agrícola, 1998, Lavras. Anais... Poços de Caldas: SBEA/UFLA, 1998, p.311-348.

TIVELLI, S.W. Manejo do ambiente em cultivo protegido. In: GOTO, R.; TIVELLI, S.W. Produção de hortaliças em ambiente protegido: condições subtropicais. São Paulo: Fundação Editora da UNESP, 1998. p.15-30. 